\title{
A SIMPLE ACCESSORY FOR THE DARKROOM
}

BY

J. SHERNE, F.R.C.S.

LEEDS

IN view of the interest shown in this little aid to the darkroom at the recent meeting of the North of England Ophthalmological Society, and as it did not figure in the programme, I thought it might be worth while introducing the idea to a larger audience.

On the darkroom wall, directly opposite to and on the same level as the retinoscopy light, is fixed a reflector such as cyclists use instead of a rear light. This picks up the light extraordinarily well, producing a brilliant red fixation spot, which even the most myopic seem to have no difficulty in seeing.

I now do the great majority of hospital refractions without a mydriatic as I feel that under proper conditions it is the most accurate method, and $I$ have found this method a great advance on the other methods I have tried of persuading the patient to relax his accommodation.

In refracting the right eye $I$ sit in front of and slightly to the left of the patient so that his view of the reflector by the right eye is obstructed by my head, but he has a clear view with the left eye. He is now asked to keep looking at the red light, so that when I am refracting the right eye, his direction of gaze is straight forward, fixing the opposite wall of the darkroom.

For refracting the left eye I shift my stool slightly to my right, so that my head now obstructs his left eye, and he fixes the reflector with his right eye. This involves using the left eye and hand for the retinoscopy, holding the lenses in the right hand. After a little practice this is not very difficult.

These reflectors are very cheap, and can be bought for a shilling at Halford's or any other cycle store. They are very easy to fix on the wall and can readily be adjusted to any height. Children seem to be more interested in them than in an ordinary spotlight and no doubt other uses for such a simple device will occur to readers.

\section{FIFTEENTH INTERNATIONAL CONGRESS OF OPHTHALMOLOGY}

ThE fifteenth quadrennial Congress was held in Cairo from December 8 to 14 under the presidency of Professor Nordenson of Stockholm. 'The first morning was occupied by the ceremonial opening of the Congress in the presence of His Majesty King Farouk. This took place in the large hall of the Egyptian 
University and was well attended by most of the 600 congressists and the 200 associate members. Speeches were delivered by the national representatives, Dr. Sinclair of Edinburgh representing Great Britain.

In the evening there was a Reception at the Semiramis Hotel by the Local Committee, during which there was a cabaret entertainment followed by a buffet supper. . On the following day, Thursday, the congressists were honoured by invitation to a reception at the Palace of Abdine by command of His Majesty. The delegates from the various countries were presented. An admirable play was given in the Palace Theatre in Arabic, the heroine of which was portrayed as being blind. After this there was a ballet by the professional ladies of the Opera House, and then excerpts from the opera, "The Barber of Seville." It should be mentioned that the orchestra was extremely good, the members of which came from the State Opera House. The King was present throughout the entertainment, and at the supper.

On Friday evening the congressists and their consorts were invited to a banquet given by the Minister of Public Health. The admirable cuisine, the wines and the attendance by the Berberine waiters are to be remembered; but Shepheard's Hotel has always been celebrated for its Lucullus feasts.

On Saturday afternoon there was an excursion to see the Pyramids and the Sphinx, with tea at Mena House Hotel. On the same evening there was the official banquet at the Semiramis Hotel. On Sunday morning a visit was paid to the Memorial Ophthalmic Laboratory; this is probably the finest ophthalmic laboratory in the world, as to architecture, design and equipment with every known ophthalmic instrument of the latest type; the arrangements for keeping the monkeys and other animals used for experimental research were especially admired. On Monday there was a visit to one of the newer ophthalmic hospitals at Rod-el-Farag, which has been built at a cost of $£ 28,000$, in the environs of Cairo. This was followed by a steamer excursion to the Delta Barrage and the wonderful gardens in the vicinity. On Tuesday one of the original travelling hospitals was visited; this commenced work in 1904, though the general equipment and amenities have been greatly improved since then, all modern ophthalmic instruments being now available.

On Monday evening there was a reception by the Minister of Public Health at the Semiramis Hotel with a buffet supper. On Tuesday afternoon there was a General Meeting at which the place for the next quadrennial Congress was decided. The suggestions were for Vienna, Warsaw and New York, the first of which was decided on. The resignation of Sir John Parsons from membership of the International Council was accepted with regret and 
Dr. Sinclair, a former President of the Ophthalmological Society of the United Kingdom was appointed in his place. Two new ex-officio members of the International Council were appointed, $\mathrm{Mr}$. MacCallan as President of the International Organisation against Trachoma, and Dr. Bailliart as President of the International Association for the Prevention of Blindness. Professor Nordenson was unanimously re-elected President of the International Council for another four years.

Every effort was made by the Egyptian members of the Local Committee to provide for the pleasure and convenience of congressists. Delightfully sunny weather was experienced during the whole of the Congress. Numbers of the congressists journeyed to Luxor and Asswan, while every one made several visits to the entrancingly interesting museums of Cairo. At no Congress has greater pleasure and interest been experienced by those who attended it.

At the scientific meetings the two main subjects discussed were :

(1) Hypertension and retinal arterio-sclerosis and

(2) Endocrinology and its relation to the eye.

Dr. H. P. Wagener and Dr. Norman M. Keith (the Mayo Clinic), Dr. Bailliart (Paris) and Dr. Y. Koyanagi (Japan) read the opening papers on the subject of retinal arterial hypertension.

The ophthalmologist, because of the wider and more intimate knowledge of the clinical details of retinal pathology, should be better equipped than the physician to observe the reactions in the retina which are associated with an elevation of blood pressure and systemic vascular disease. If it can be assumed, as seems logical, that the visible reactions in the retinal vessels are similar, though at times disproportionate, to the invisible reactions taking place in vessels of similar size throughout the body, it is obvious that an explanation of the mechanism of these reactions in the retina will go far toward solving the mechanism of diffuse vascular disease. The responsibility of the ophthalmologist in the solution of this problem is great, and his opportunities are wide, for he is able to see these vascular changes from their inception and to study their modes of origin and progression.

Evidence accumulated in the fields of physiology, pathology and clinical investigation seems to indicate rather conclusively that arterial hypertension is an expression of a diffuse disease or abnormal condition of the arterioles throughout the body. The lesion of the arterioles results in an increase in the peripheral resistance in certain regions or in the whole of the arteriolar bed. The narrowing of the lumen of the arterioles, which is the apparent cause of the increased resistance is not structural in the earliest 
phases of the disease. It must be regarded as due to increased tonicity of the vessel wall, to spastic constriction, or to a combination of the two. Whether the tonic or spastic constriction is due to the action of a pressor substance directly on the arteriolar wall or through the medium of the sympathetic nerves, or simply to increased vasomotor stimuli is not known. If the causative factor of the arteriolar narrowing continues to operate, histologic changes develop ultimately in various parts of the arteriolar system, for example, in the peripheral muscles, the heart, the kidney, the brain and the retina.

Both these factors, functional narrowing of and structural wall changes in arterioles, appear to be present in the usual case of diffuse arteriolar disease of the so-called "essential hypertension " type. On the basis largely of the dominance of one or the other of these factors in a particular case, it is possible to classify cases of " essential" hypertension into various groups, in each of which the probable course of the disease and the life expectancy of the individual patient can be foretold with a reasonable degree of accuracy.

Dumas divided essential hypertension into three phases: In the first or silent phase the patient is essentially symptomless. In the second or established phase the disease has become organic and visceral lesions are present. Cerebral haemorrhages, cardiac failure or uraemia may terminate this phase. It is possible, however, for the hypertension to pass into the third or involutional phase, in which the blood pressure drops and arteriosclerosis dominates the picture-the hypotensive stage of hypertension. According to Bonamour, the retinal changes in Dumas' first phase are spastic in type. The blood pressure in the central artery of the retina is likely to be elevated disproportionately to the blood pressure in the brachial arteries. Patients may complain of transient loss of vision. Post-spastic thrombosis of the central artery may result in permanent loss of vision. In the second or established phase, retinitis develops in cases which are running a rapidly progressive course. If the disease progresses more slowly, sclerosis develops in the retinal arteries as a defence reaction. In the third or involutional phase, the sclerosis in the retinal arteries is likely to be quite marked, and lesions such as arteriosclerotic retinitis and retinitis circinata are characteristic. In Bonamour's opinion, retinitis of the hypertensive type is essentially vasospastic in origin. As a result of arteriolar constriction reactional dilation and stasis develop in the capillary bed and serous and haemorrhagic transudations take place into the retina.

The problem of the pathogenesis of "albuminuric retinitis" has been a consuming one almost since the beginnings of our 
knowledge of albuminuria as an expression of disease of the kidneys. Bright himself recognised that loss of vision was a symptom in cases of certain patients with albuminuria.

Most physicians at present agree that a retinitis of "albuminuric type" can occur in cases in which no evidence of renal insufficiency can be demonstrated clinically, and in which, at necropsy, the kidneys show no evidence of primary nephritis.

The most logical explanation of the mode of origin of " albuminuric retinitis" seems to be that of Volhard, who regarded both the arteriolar sclerosis of Verwey and the retinitis as a result of ischaemia due to spasm in the larger arterioles. Volhard's conception of ischaemic or angiospastic retinitis seems to be more generally applicable than any other to the retinal complications of hypertension and nephritis and to permit of more ready comparison of these complications with the other features of the systemic disease.

Wagener and Keith reported in 1923 on a condition which they termed " the malignant hypertension syndrome." The objective findings are persistently elevated blood pressure, diffuseness of arterial and arteriolar thickening throughout the body, minimal changes in parenchyma of kidney and retinal changes. The important retinal alterations are the marked spastic and organic narrowing of the arterioles, with diffuse retinitis and oedema of the discs. The characteristic symptoms are nervousness, asthenia, visual disturbances, dyspnoea on exertion. All observers are agreed that the patients of this group are in very serious condition. A follow-up of 146 cases showed that 80 per cent. of them died within one year.

Dr. Bailliart, dealing with the clinical part of retinal arterial hypertension, stressed the value of his dynamometer which estimates the diastolic blood pressure in the retinal arterioles, which is about 40 per cent. of the diastolic pressure in the brachial arteries. The pressures as measured by this method furnish a ready and probably fairly reliable method of determining variations from the normal in pathological states.

The discussion on endocrinology and its relation to the eye was opened by Dr. Snapper (Holland), Dr. von Szily (Germany), Dr. von J. Imre (Hungary), Drs. Jeandelize and Drouet (France), and Dr. Le Cascio (Italy).

Recent investigations have shown that various disorders of the sexual glands are associated with pathological changes occurring in the eyes. Periodic haemorrhages of the subconjunctival tissue, recurring conjunctival inflammations, or especially phlyctenular kerato-conjunctivitis are not rarely found in close relation to menstruation. Filamentary keratitis following atrophy of the lacrimal glands and often combined with arthritic processes, as a 
rule develop in women with ovarian disorders or in the beginning of the climacteric.

Keratoconus has been shown in many instances to be a manifestation of disorders of endocrine glands (thyroid and gonads). Von Imre is of opinion that there is a close connection between acute and chronic glaucoma and abnormal folliculin production. The folliculin production of four glaucomatous patients, examined by reliable biological methods, proved to be exceedingly low. The production of prolan was in every case normal. He points out that there is an undoubted connection between the changes of the intra-ocular tension and the pituitary during pregnancy.

Patients suffering from retinitis pigmentosa are treated nowadays with Menformon and in many cases improvement follows and the progression of the disease is arrested.

At the meeting of the International Organisation against Trachoma Mr. A. F. MacCallan, President of the Organisation, gave an introductory address. Dr. Rowland P. Wilson read a paper on the pathology of Trachoma. The theory of bacterial origin of trachoma has been abandoned. Attention is concentrated mainly on its resemblance to disease caused by known viruses. In Egypt, 90 per cent. of the population is still trachoma infected. The question of reduction of this permanent scourge is closely connected with the social conditions prevailing in Egypt. The excellent work done at present in Egyptian hospitals can only diminish complications resulting from trachoma and thus reduce the incidence of blindness.

At the meeting of the International Association for Prevention of Blindness, Dr. Bailliart (president) read an introductory address. $\mathrm{Mr}$. MacCallan (London) gave an introductory address. Dr. F. Park Lewis (New York) discussed the responsibility of the ophthalmologist in the conservation of sight and the prevention of blindness. The prevention of blindness is as worthy of consideration by ophthalmologists as either research or surgical care in affections of the eyes. The blindness that comes from negligence, from ignorance, from indifference and the crudities of living and its mismanagement is universal. The proportion of eyes that are lost and might be saved by preventive measures is greater and the results better than those in which sight is restored by science and by surgical skill.

Dr. Joseph Minton (London) read a paper on prevention of industrial eye injuries. An investigation was carried out by him at the Royal Eye Hospital, London, where over 7,000 patients are attended to every year suffering from industrial eye injuries. The present high numbers are due to (1) non-provision of safety measures by employers and (2) the attitude of indifference shown by workmen to the risks entailed in their work and their negligence 
in using preventive measures supplied to them. Following the above investigation of industrial eye injuries he has organised at the Royal Eye Hospital a museum of preventive measures at the hospital outpatient rooms. The patients have thus an opportunity of studying the preventive appliances at the time of attendance at the hospital and thus choosing the most suitable one for their type of work. If other hospitals situated in industrial centres will take an interest in preventive work, a diminution of eye injuries and with it of its resultant total or partial blindness would follow.

Mr. Lewis H. Carris (U.S.A.) read a paper on the rôle of the social worker in a prevention of blindness campaign. Educators, public health officials, nurses, industrialists, sanitary engineers, social workers and all in any way concerned in human welfare must take their rightful place in this attack upon this social enemy. To the world at large we must teach the causes of blindness and of defective vision, the place of nutrition and hygiene in relation to eye health, methods of safeguarding the eye aginst injury and harm and of keeping it in a state of greatest possible usefulness

\section{INTERNATIONAL ORGANIZATION AGAINST TRACHOMA}

\section{Executive Committee}

A Meeting of the Executive Committee was held on December 9, 1937, at the Semiramis Hotel, Cairo.

The Secretary General read the Minutes of the last Meeting of the Executive Committee held in Paris in 1936. The accounts were examined and found to be correct. The subvention given for purposes of research by the American Academy of Ophthalmology and Oto-Laryngology, 100 dollars, was allocated to Dr. Poleff of the Pasteur Institute at Rabat, Morocco. It was decided to hold the next meeting of the Organization at the same place, and at the same time, as the next Meeting of the International Council of Ophthalmology in the year 1939 .

\section{Assembly of Delegates}

An Assembly of delegates was held on December 10, 1937, at the Semiramis Hotel, Cairo.

A statement was made by the President as to the business to be transacted. The audited accounts were passed. Professor Manuel Marquez was elected an Honorary Member of the Executive Committee. 